\title{
Correction to: Mathematical analysis of robustness of two-level domain decompositionmethods with respect to inexact coarse solves
}

\section{Frédéric Nataf ${ }^{1}$}

Published online: 23 September 2020

(c) Springer-Verlag GmbH Germany, part of Springer Nature 2020

\section{Correction to: Numerische Mathematik (2020) 144:811-833 https://doi.org/10.1007/s00211-020-01102-6}

I bring to the attention of the readers two errors in the formulas of the article. The big picture is unchanged but nevertheless, I think it would be helpful to make them known to the readers. There are also minor typos.

Formula (17) should read:

$$
c_{R}:=\frac{k_{0}\left(1+\epsilon_{A}^{2}\right)+\lambda_{\max }\left(E \tilde{E}^{-1}\right)+\sqrt{\left(k_{0}\left(1+\epsilon_{A}^{2}\right)-\lambda_{\max }\left(E \tilde{E}^{-1}\right)\right)^{2}+4 \lambda_{\max }\left(E \tilde{E}^{-1}\right) k_{0} \epsilon_{A}^{2}}}{2} .
$$

Formula (21) should read:

$$
c_{T}=\frac{\lambda_{\min }\left(E \tilde{E}^{-1}\right)}{\left(1+\epsilon_{A} \sqrt{k_{0} k_{1} \tau}\right)^{2}+\lambda_{\min }\left(E \tilde{E}^{-1}\right) k_{1} \tau} .
$$

Formula (34) should read:

$$
c_{R}:=\frac{k_{0} \gamma\left(1+\epsilon_{A}^{2}\right)+\lambda_{\max }\left(E \tilde{E}^{-1}\right)+\sqrt{\left(k_{0} \gamma\left(1+\epsilon_{A}^{2}\right)-\lambda_{\max }\left(E \tilde{E}^{-1}\right)\right)^{2}+4 \lambda_{\max }\left(E \tilde{E}^{-1}\right) k_{0} \gamma \epsilon_{A}^{2}}}{2} .
$$

Also minor typos are the following:

- Page 820, between (19) and (20) in the bound for the A-norm of FU: in the first line $\left\|P_{0} U, P_{0} U\right\|_{A}^{2}$ should be $\left\|P_{0} U\right\|_{A}^{2}$

The original article can be found online at https://doi.org/10.1007/s00211-020-01102-6.

Frédéric Nataf

frederic.nataf@sorbonne-universite.fr

1 Laboratoire J.L. Lions, UPMC, CNRS UMR7598, Equipe LJLL-INRIA Alpines, 4 Place Jussieu, 75005 Paris, France 
- Page 826, at the end of the first sentence it says $V_{\tau}+W+$. The hanging + sign is there at the end and this should not be the case.

- Page 828, between (36) and (37), the same mistake as Page 820 above.

- Page 829, in (40) in the final term the size of the ) are wrong: the big right bracket should be the first one while the small right bracket should be the last one.

I thank Niall Bootland, research associate at University of Strathclyde, for suggesting me the corrections.

Publisher's Note Springer Nature remains neutral with regard to jurisdictional claims in published maps and institutional affiliations. 